\title{
Vanadate-Induced Renal cAMP and Malondialdehyde Accumulation Suppresses Alpha 1 Sodium Potassium Adenosine Triphosphatase Protein Levels
}

\author{
Somchit Eiam-Ong ${ }^{1}$, Yuyen Nakchui ${ }^{2}$, Mookda Chaipipat ${ }^{3}$ and Somchai Eiam-Ong ${ }^{4}$ \\ ${ }^{1}$ Department of Physiology, Faculty of Medicine, Chulalongkorn University, Bangkok, Thailand \\ ${ }^{2}$ School of Medicine, Walailak University, Nakhonsrithammarat, Thailand \\ ${ }^{3}$ Department of Pathology, Faculty of Medicine, Chulalongkorn University, Bangkok, Thailand \\ ${ }^{4}$ Division of Nephrology, Department of Medicine, Faculty of Medicine, Chulalongkorn University, Bangkok, Thailand
}

\begin{abstract}
It has been demonstrated that vanadate causes nephrotoxicity. Vanadate inhibits renal sodium potassium adenosine triphosphatase ( $\mathrm{Na}, \mathrm{K}$-ATPase) activity and this is more pronounced in injured renal tissues. Cardiac cyclic adenosine monophosphate (cAMP) is enhanced by vanadate, while increased cAMP suppresses Na, K-ATPase action in renal tubular cells. There are no in vivo data collectively demonstrating the effect of vanadate on renal cAMP levels; on the abundance of the alpha 1 isoform $\left(\alpha_{1}\right)$ of the Na, K-ATPase protein or its cellular localization; or on renal tissue injury. In this study, rats received a normal saline solution or vanadate $(5 \mathrm{mg} / \mathrm{kg} \mathrm{BW})$ by intraperitoneal injection for 10 days. Levels of vanadium, cAMP, and malondialdehyde (MDA), a marker of lipid peroxidation were measured in renal tissues. Protein abundance and the localization of renal $\alpha_{1}$-Na, K-ATPase was determined by Western blot and immunohistochemistry, respectively. Renal tissue injury was examined by histological evaluation and renal function was assessed by blood biochemical parameters. Rats treated with vanadate had markedly increased vanadium levels in their plasma, urine, and renal tissues. Vanadate significantly induced renal cAMP and MDA accumulation, whereas the protein level of $\alpha_{1}$-Na, K-ATPase was suppressed. Vanadate caused renal damage, azotemia, hypokalemia, and hypophosphatemia. Fractional excretions of all studied electrolytes were increased with vanadate administration. These in vivo findings demonstrate that vanadate might suppress renal $\alpha_{1}-\mathrm{Na}$, K-ATPase protein functionally by enhancing cAMP and structurally by augmenting lipid peroxidation.
\end{abstract}

Key words: Vanadate, cAMP, MDA, $\alpha_{1}-\mathrm{Na}, \mathrm{K}-\mathrm{ATP}$ ase protein, Rat kidney

\section{INTRODUCTION}

Vanadate, an oxyanion derivative of vanadium, is present at various concentrations in soil, water, air, plants, animals and human tissue $(1,2)$. It has been demonstrated that vanadate is a potent inhibitor of $\mathrm{H}, \mathrm{K}$-ATPase activity

Correspondence to: Somchit Eiam-Ong, Department of Physiology, Faculty of Medicine, Chulalongkorn University, Bangkok 10330, Thailand

E-mail: eiamong@yahoo.com

This is an Open-Access article distributed under the terms of the Creative Commons Attribution Non-Commercial License (http:// creativecommons.org/licenses/by-nc/3.0) which permits unrestricted non-commercial use, distribution, and reproduction in any medium, provided the original work is properly cited.
$(3,4)$. A previous study showed that chronic vanadate administration reduced the collecting tubule $\mathrm{H}, \mathrm{K}$-ATPase activity and induced hypokalemic distal renal tubular acidosis (5). Moreover, vanadate also is a potent blocker of $\mathrm{Na}$, K-ATPase $(6,7)$. In renal tissue homogenate, vanadate diminished $\mathrm{Na}$, K-ATPase activity in a dose dependent response (8). Chronic vanadate administration inhibited $\mathrm{Na}, \mathrm{K}$-ATPase activity in microdissected collecting ducts (5). Histochemistry revealed that rats exposed to vanadate had reduced $\mathrm{Na}$, K-ATPase protein immunoreactivity in morphologically altered nephrons (9). In addition, vanadate increased lipid peroxidation presented as malondialdehyde (MDA) levels and caused renal tissue damages (10-13).

In the heart, vanadate stimulated adenylate cyclase and 
enhanced cAMP levels (14-16). In the kidney, administration of cAMP caused a reduction in Na, K-ATPase activity in the medullary thick ascending limb and in the cortical collecting ducts (17). However, there are no in vivo studies of cAMP concentration in renal tissues after vanadate administration.

There is currently no single study that documents the in vivo effect of vanadate on renal cAMP levels, $\alpha_{1}-\mathrm{Na}, \mathrm{K}-$ ATPase protein abundance/localization, and renal tissue injury. Therefore, this study examined rat kidneys 10 days following injection of normal saline or vanadate. Western blot analysis and immunohistochemistry were performed to determine the protein abundance and the localization of renal $\alpha_{1}$-Na, K-ATPase. Tissue accumulations of vanadium, cAMP, and MDA were measured. Renal tissue injury and renal function were also examined.

\section{MATERIALS AND METHODS}

Experimental design. Male Wistar rats weighing 200 $240 \mathrm{~g}$ (National Center of Scientific Use of Animals, Mahidol University, Nakornpathom, Thailand) were given a conventional diet and housing. All animal protocols were approved by the Ethics Committee of Research, Chulalongkorn University, Bangkok, Thailand (permit number 108/2000). The rats were maintained at $23 \sim 25^{\circ} \mathrm{C}$ under a light-dark cycle of $12 \mathrm{hr}$, and the animals were allowed ad libitum access to laboratory chow and water. Normal serum creatinine for rats is $<1 \mathrm{mg} / \mathrm{dL}(18-20)$. The rats were divided into two groups ( $\mathrm{n}=8 /$ group): sham (normal saline solution; NSS: $0.5 \mathrm{~mL} / \mathrm{kg}$ BW by intraperitoneal injection; i.p.); and vanadate $(5 \mathrm{mg} / \mathrm{kg} \mathrm{BW}$; diluted in NSS; i.p.). Both groups received their treatment for 10 days. We used this dose of vanadate as previously performed in the study on renal H, K-ATPase protein expression (21). Therefore, in the present investigation, we further examine the effect of this dose on renal cAMP levels, $\alpha_{1}$-Na, K-ATPase protein abundance/localization, and renal tissue injury.

One day before the experiment, the rats were placed in metabolic cages for 24-hr urine collection. On the date of the experiment, they were anesthetized by thiopental $(100 \mathrm{mg} / \mathrm{kg} \mathrm{BW}$; i.p.). Plasma samples collected from the abdominal aorta were stored at $-80^{\circ} \mathrm{C}$ until they were measured for vanadium levels using an atomic absorption spectrophotometer (Model 4110ZLAA spectrometer, Perkin-Elmer Co., Ueberlingen, Germany). Blood and urine chemistry were measured via an indirect method (Model CX3, Beckman, Krefeld, Germany) (18-21).

The kidneys were removed. Half of each kidney was fixed in liquid nitrogen and then stored at $-80^{\circ} \mathrm{C}$ until measurement of $\alpha 1-\mathrm{Na}$, K-ATPase protein abundance by Western blot analysis. The other half of the renal tissue was fixed in $10 \%$ paraformaldehyde for determination of protein localization by immunohistochemistry and for renal injury by histopathological examination. Vanadium levels in renal tissue samples from the cortex and the medulla were also measured as previously described (21).

Western blot analysis. Protein abundance was detected using $8 \%$ sodium dodecyl sulfate polyacrylamide gel electrophoresis (SDS-PAGE) as previously described (18-20). The proteins were transferred onto nitrocellulose membranes (Bio-Rad, Hercules, CA, USA) and then the membranes were incubated with a primary monoclonal antibody to $\alpha_{1}$-Na, K-ATPase (C464.6; 1:2500; Millipore, Temecula, CA, USA) (19) or to $\beta$-actin (Santa Cruz Biotechnology, Dallas, TX, USA), followed by the respective horseradish peroxidase-linked secondary antibody (BioRad). Immunoreactive proteins were detected by chemiluminescence (SuperSignal West Pico kit; Pierce, Rockford, IL, USA) and documented using a molecular imager ChemiDoc XRS system (Bio-Rad). The relative protein level of $\alpha_{1}$-Na, K-ATPase in each sample is presented as a percentage of the control normalized to its $\beta$-actin content (18-20).

Immunohistochemical study. Detection of protein localization was performed as previously described (1820). Paraffin-embedded kidney sections were cut to $4 \mu \mathrm{m}$ in thickness. The slides were deparaffinized, and endogenous peroxidase was blocked by treatment with $3 \% \mathrm{H}_{2} \mathrm{O}_{2}$. The sections were incubated with the primary antibody of $\alpha_{1}$-Na, K-ATPase (1:2000; Millipore) at $4^{\circ} \mathrm{C}$ overnight followed by the respective horseradish peroxidase-linked secondary antibody (Bio-Rad) and then reacted with 3, 3'diaminobenzidine (DAB) solution (Sigma, St. Louis, MO, USA). The immunostaining intensity was scored in a blinded manner on a semi-quantitative five-tiered grading scale from 0 to $4(0=$ negative; $1=$ trace; $2=$ weak; $3=$ moderate; $4=$ strong) as previously described (18-20).

Malondialdehyde (MDA) measurement. MDA levels in the kidney were determined by following a protocol as previously described for the thiobarbituric acid reaction method and were used as an indicator of lipid peroxidation (LPO) (22). In brief, the renal tissues were weighed and homogenized in $1.15 \% \mathrm{KCl}(1 \mathrm{~g}$ of renal tissue in $9 \mathrm{~mL}$ of $\mathrm{KCl}$ ) for $1 \mathrm{~min}$. A $0.2 \mathrm{~mL}$ aliquot of the homogenate was added to a reaction mixture containing $0.2 \mathrm{~mL}$ of $8.1 \%$ sodium dodecyl sulfate (w/v), $1.5 \mathrm{~mL}$ of $20 \%$ acetic acid $(\mathrm{v} / \mathrm{v}), 1.5 \mathrm{~mL}$ of $0.8 \%$ thiobarbituric acid $(\mathrm{w} / \mathrm{v})$, and $0.6 \mathrm{~mL}$ of distilled water. The samples were mixed vigorously and then heated in a water bath (WNB10, Memmert, Schwabach, Germany) at $95^{\circ} \mathrm{C}$ for $60 \mathrm{~min}$. After cooling with tap water, the samples were added to $1 \mathrm{~mL}$ of distilled water and $5 \mathrm{~mL}$ of a mixture of n-butanol and pyridine $(15: 1, \mathrm{v} / \mathrm{v}$; Sigma) and shaken vigorously (at least $1 \mathrm{~min})$. 
The mixtures were centrifuged at $1,200 \mathrm{~g}$ for $15 \mathrm{~min}$. The organic layer was removed and the absorbance at $532 \mathrm{~nm}$ was measured with a spectrophotometer (Optima Inc, SP3000plus, Tokyo, Japan). A standard curve of 0 to 200 $\mathrm{nmol} / \mathrm{mL}$ malondialdehyde bis(dimethyl acetal 99\%; Sigma) in water was prepared. The content of LPO was reported as nmol of MDA per mg of protein. Measurements of all samples were conducted in duplicate (22).

Cyclic adenosine monophosphate (CAMP) measurement. Renal cAMP concentrations were measured by an enzyme-linked immunosorbent assay (ELISA) following the manufacturer's protocol (Mouse/rat cAMP Parameter Assay Kit, KGE 012B; R\&D system; Minneapolis, $\mathrm{MN}, \mathrm{USA}$ ). The principle of this assay is based on a competitive binding technique in which the cAMP that is present in a sample or standard competes with a fixed amount of horseradish peroxidase-labeled cAMP for sites on a mouse monoclonal antibody. During the incubation, the monoclonal antibody binds to the goat anti-mouse antibody coating the microplate. Following a wash to remove excess conjugate and unbound sample, the substrate solution is added to the wells to determine the bound enzyme activity. The color development was stopped and the absorbance was read at $450 \mathrm{~nm}$. The concentration of cAMP was reported as nmol/mg protein. Measurements of all samples were conducted in duplicate.

Morphological evaluation. Renal morphological changes were assessed using longitudinal, 4- $\mu \mathrm{m}$ thick kidney sections stained with Periodic Acid-Schiff (PAS) as previously described $(22,23)$.

Statistical analysis. The results from parameters of blood, urine, tissue, and renal $\alpha_{1}$-Na, K-ATPase protein abundance were expressed as the mean \pm SD. Statistical

Table 1. Blood and tissue biochemical parameters of the rats after 10 days of vanadate injection

\begin{tabular}{|c|c|c|}
\hline \multirow{2}{*}{ Parameters } & \multicolumn{2}{|c|}{ Groups } \\
\hline & Sham & Vanadate \\
\hline Plasma vanadate $(\mathrm{ng} / \mathrm{mL})$ & $0.17 \pm 0.09$ & $1,947.50 \pm 124.11^{* *}$ \\
\hline Urine vanadate $(\mathrm{ng} / \mathrm{mL})$ & $0.38 \pm 0.05$ & $2,658.20 \pm 78.15^{* * *}$ \\
\hline Tissue vanadate (cortex) ( $\mu \mathrm{g} / \mathrm{g}$ dry wt.) & $0.18 \pm 0.03$ & $114.73 \pm 4.39 * * *$ \\
\hline (medulla) ( $\mu \mathrm{g} / \mathrm{g}$ dry wt.) & $0.57 \pm 0.09$ & $26.49 \pm 4.65^{* *}$ \\
\hline Tissue c-AMP (cortex) (nmol/mg protein) & $0.33 \pm 0.02$ & $0.77 \pm 0.13^{*}$ \\
\hline (medulla) (nmol/mg protein) & $0.35 \pm 0.01$ & $0.63 \pm 0.04^{*}$ \\
\hline Tissue MDA (cortex) (nmol/g wet wt.) & $35.96 \pm 0.95$ & $65.46 \pm 6.34^{*}$ \\
\hline (medulla) (nmol/g wet wt.) & $18.39 \pm 0.31$ & $50.18 \pm 0.66^{*}$ \\
\hline Blood urea nitrogen $(\mathrm{mg} / \mathrm{dL})$ & $22.73 \pm 0.74$ & $51.00 \pm 5.49^{* *}$ \\
\hline Creatinine $(\mathrm{mg} / \mathrm{dL})$ & $0.42 \pm 0.01$ & $0.83 \pm 0.06^{* * *}$ \\
\hline Plasma potassium $(\mathrm{mmol} / \mathrm{L})$ & $3.85 \pm 0.22$ & $3.00 \pm 0.11^{* *}$ \\
\hline Plasma phosphate (mg/dL) & $8.91 \pm 0.12$ & $7.67 \pm 0.28^{*}$ \\
\hline Plasma sodium $(\mathrm{mmol} / \mathrm{L})$ & $142.18 \pm 0.50$ & $141.31 \pm 0.50$ \\
\hline Plasma chloride $(\mathrm{mmol} / \mathrm{L})$ & $105.82 \pm 0.79$ & $103.44 \pm 0.73$ \\
\hline Plasma bicarbonate $(\mathrm{mmol} / \mathrm{L})$ & $25.63 \pm 0.49$ & $25.23 \pm 0.77$ \\
\hline Blood pH & $7.45 \pm 0.01$ & $7.42 \pm 0.02$ \\
\hline
\end{tabular}

Abbreviations: MDA, Malondialdehyde; wt., weight. Data are expressed as the mean $\pm S D(n=8)$.

${ }^{*} p<0.05,{ }^{* *} p<0.01,{ }^{* *} p<0.001$ versus the sham group.

Table 2. Renal function parameters of the rats after 10 days of vanadate injection

\begin{tabular}{lcc}
\hline \hline & \multicolumn{2}{c}{ Groups } \\
\cline { 2 - 3 } Parameters & \multicolumn{1}{c}{ Sham } & Vanadate \\
\hline Creatinine clearance $(\mathrm{mL} / \mathrm{min} / 100 \mathrm{~g} \mathrm{BW})$ & $0.92 \pm 0.02$ & $0.15 \pm 0.01^{* *}$ \\
FE potassium (\%) & $54.09 \pm 2.65$ & $132.66 \pm 9.94^{*}$ \\
FE phosphate (\%) & $7.09 \pm 1.26$ & $58.77 \pm 4.86^{* *}$ \\
FE bicarbonate (\%) & $2.26 \pm 0.36$ & $23.98 \pm 2.73^{* *}$ \\
FE sodium (\%) & $0.52 \pm 0.03$ & $1.12 \pm 0.21^{* *}$ \\
FE chloride (\%) & $1.12 \pm 0.09$ & $2.71 \pm 0.37^{*}$ \\
Urine flow rate (mL/day/100 g BW) & $13.99 \pm 1.43$ & $10.29 \pm 0.98$ \\
\hline
\end{tabular}

Abbreviations: $F E$, fractional excretion; BW, body weight. Data are expressed as the mean $\pm S D(n=8)$.

${ }^{*} p<0.05,{ }^{* *} p<0.01$ versus the sham group. 
differences between the groups were assessed by an ANOVA (analysis of variance) with a post hoc comparison by Tukey's test when appropriate. A $p$ value of $<0.05$ was considered statistically significant. Statistical tests were conducted using SPSS program version 22.0 (SPSS Inc, Chicago, IL, USA). The median staining intensity (score) of renal $\alpha_{1}$-Na, K-ATPase protein levels was presented as previously described (18-20).

\section{RESULTS}

\section{Changes in blood and tissue biochemistry and renal} function parameters. As illustrated in Table 1, 10-day vanadate administration significantly increased vanadium levels in plasma, urine, and renal tissues. The cortical region had more vanadium deposition (from $0.18 \pm 0.03$ $\mu \mathrm{g} / \mathrm{g}$ dry wt. to $114.73 \pm 4.39 \mu \mathrm{g} / \mathrm{g}$ dry wt.; $p<0.001$ ) than the medulla area (from $0.57 \pm 0.09 \mu \mathrm{g} / \mathrm{g}$ dry wt. to $26.49 \pm$ $4.65 \mu \mathrm{g} / \mathrm{g}$ dry wt.; $p<0.01)$. Vanadate induced tissue cAMP accumulation approximately two times in both the cortex (from $0.33 \pm 0.02 \mathrm{nmol} / \mathrm{mg}$ protein to $0.77 \pm 0.13 \mathrm{nmol} /$ $\mathrm{mg}$ protein; $p<0.05$ ) and the medulla (from $0.35 \pm 0.01$

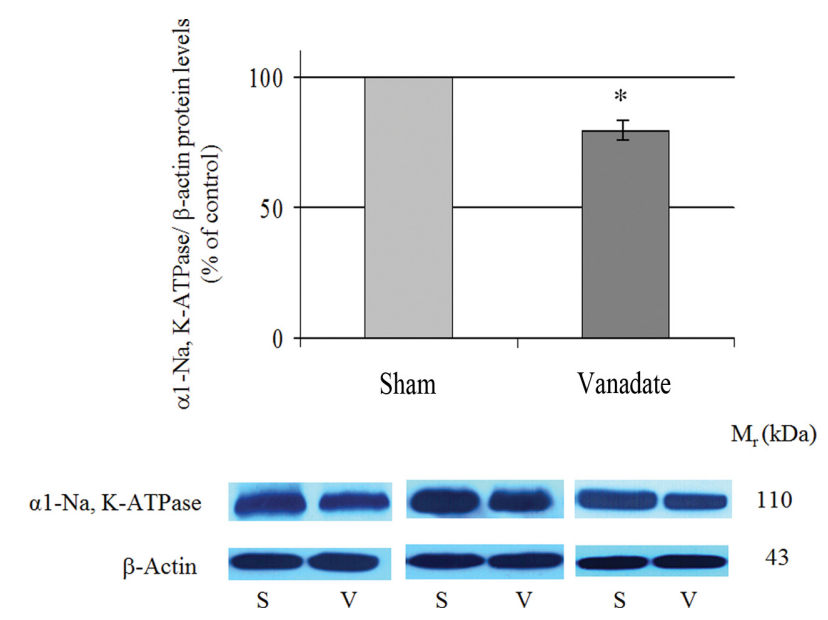

Fig. 1. Effect of vanadate on renal $\alpha_{1}-\mathrm{Na}, \mathrm{K}$-ATPase protein abundance. Ten days of vanadate injection significantly suppressed $\alpha_{1}-\mathrm{Na}$, K-ATPase protein abundance. Histogram bars show the densitometric analyses ratios of $\alpha_{1}-\mathrm{Na}$, K-ATPase to $\beta$-actin intensity, and the representative immunoblot photographs are present. All values are expressed as the mean \pm SD of 8 rats/group. *Significantly different from the sham group $(p<0.05)$ (S: sham; V: vanadate).
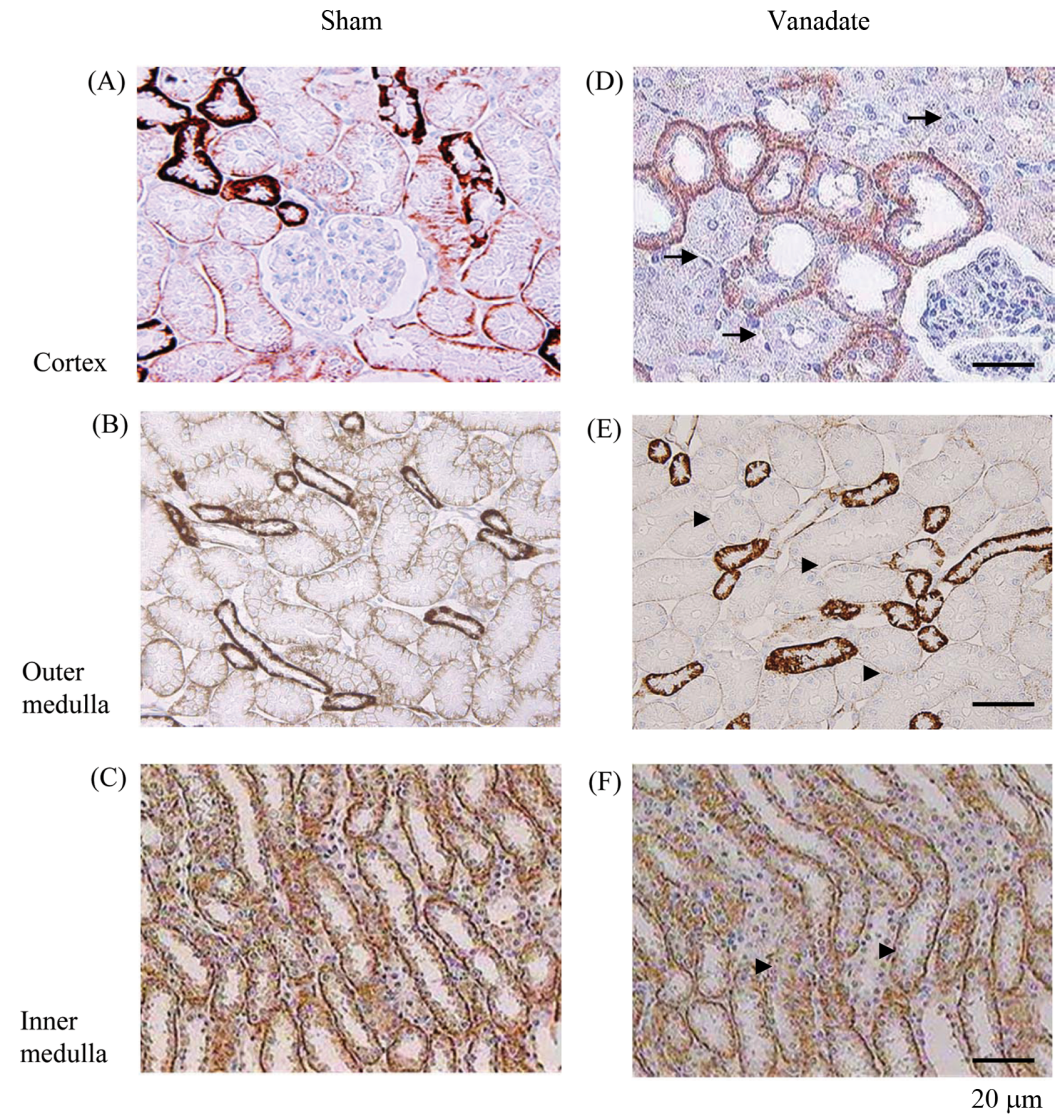

Fig. 2. Representative immunohistochemical staining images of renal $\alpha_{1}-\mathrm{Na}, \mathrm{K}$-ATPase protein localization in the cortex (A, D), outer medulla $(B, E)$, and inner medulla $(C, F)$ from sham $(A-C)$, and vanadate $(D-F)(n=5 /$ group). Vanadate reduced immunoreactivity both in the cortex (PCT and Pcap; arrows) and the medulla (PTs and MCD; arrow heads). Bar scale $=20 \mu \mathrm{m}$. 
$\mathrm{nmol} / \mathrm{mg}$ protein to $0.63 \pm 0.04 \mathrm{nmol} / \mathrm{mg}$ protein; $p<$ $0.05)$. Blood urea nitrogen and creatinine levels were doubled by vanadate. Vanadate caused hypokalemia (from $3.85 \pm 0.22 \mathrm{mmol} / \mathrm{L}$ to $3.00 \pm 0.11 \mathrm{mmol} / \mathrm{L} ; p<0.01)$ and hypophosphatemia (from $8.91 \pm 0.12 \mathrm{mg} / \mathrm{dL}$ to $7.67 \pm 0.28$ $\mathrm{mg} / \mathrm{dL} ; p<0.05)$. Vanadate induced kaliuresis and natriuresis (Table 2). Fractional excretions of phosphate, bicarbonate, and chloride were markedly enhanced, whereas plasma sodium, chloride, bicarbonate, urine flow rate, and blood $\mathrm{pH}$ remained unchanged after vanadate treatment.

Protein abundance of renal $\alpha_{\mathbf{1}}-\mathrm{Na}, \mathbf{K}$-ATPase. Western blot analysis revealed that vanadate significantly reduced renal $\alpha_{1}-\mathrm{Na}, \mathrm{K}$-ATPase protein abundance relative to the sham group, from $100 \%$ to $79 \pm 5 \%(n=8 /$ group $)$ in the vanadate group $(p<0.05)$, as illustrated at $110 \mathrm{kDa}$ (Fig. 1).

Protein localization of renal $\alpha_{1}-\mathrm{Na}, \mathrm{K}$-ATPase. The immunohistochemical detection of $\alpha_{1}-\mathrm{Na}$, K-ATPase protein localization in renal tissues is shown in Fig. 2. The protein was observed in the tubular epithelium and in the

Table 3. Median staining intensity (score) of renal $\alpha_{1}-\mathrm{Na}, \mathrm{K}$ ATPase protein expression of the rats after 10 days of vanadate injection ( $n=5 /$ group)

\begin{tabular}{lcc}
\hline \hline & \multicolumn{2}{c}{ Median staining intensity (score) } \\
\cline { 2 - 3 } & \multicolumn{2}{c}{$\alpha_{1}$-Na, K-ATPase } \\
\cline { 2 - 3 } Sham & Vanadate \\
\hline Cortex & & 0 \\
Glomerulus & 0 & 0 \\
PCT & 3 & 3 \\
DCT & 4 & 3 \\
CCD & 4 & 0 \\
Pcap & 1 & \\
Outer medulla & & 1 \\
PTs & 3 & 4 \\
TALH & 4 & 4 \\
MCD & 4 & 3 \\
\hline Inner medulla & & 1 \\
MCD & 4 & 1 \\
tLH & 1 & \\
VR & 1 & \\
\hline
\end{tabular}

Staining intensity scores: $0=$ negative, no reactivity; $1=$ trace, faint or pale brown staining with less membrane reactivity; $2=$ weak, light brown staining with incomplete membrane reactivity; $3=$ moderate, shaded of brown staining of intermediate darkness with usually almost complete membrane reactivity; $4=$ strong, dark brown to black staining with usually complete membrane pattern, producing a thick outline of the cell (18-20).

Abbreviations: PCT, Proximal convoluted tubule; DCT, distal convoluted tubule; CCD, cortical collecting duct; Pcap, peritubular capillary; PTs, proximal straight tubule; TALH, thick ascending limb of Henle's loop; MCD, medullary collecting duct; VR, vasa recta; $\mathrm{tLH}$, thin limb of Henle's loop. vasculature but not in the glomeruli. Immunostaining of $\alpha_{1}-\mathrm{Na}, \mathrm{K}-\mathrm{ATPase}$ protein was present at the basolateral membranes in both the cortex and medulla. In the cortex of the sham group (Fig. 2A, Table 3), staining was strong $($ score $=4)$ in the distal convoluted tubules $(\mathrm{DCT})$ and the cortical collecting ducts (CCD), whereas staining was moderate $($ score $=3$ ) in the proximal convoluted tubules $(\mathrm{PCT})$ and only in a trace level $($ score $=1)$ in the peritubular capillary (Pcap). Vanadate completely abolished $\alpha_{1}-\mathrm{Na}$, K-ATPase protein immunoreactivity in the PCT and Pcap, while immunostaining in the DCT and the CCD was reduced to moderate levels (Fig. 2D).

In the outer medulla of the sham group, the intensity score was 4 in the thick ascending limb of the loop of Henle (TALH) and in the medullary collecting ducts (MCD), while the score was 3 in the proximal straight tubules (PTs) (Fig. 2B, Table 3). Vanadate suppressed the immunoreactivity in the PTs from 3 to 1 (Fig. 2E). In the inner medulla, vanadate reduced the staining from 4 to 3 in the MCD (Fig. 2C, 2F). The intensity scores in the TALH, the vasa recta, and the thin limb of the loop of Henle ( $t L H)$ remained unchanged.

\section{Evaluation of lipid peroxidation levels and renal} morphology. Vanadate significantly enhanced renal MDA levels in both the cortex (from $35.96 \pm 0.95 \mathrm{nmol} / \mathrm{g}$ wet wt. to $65.46 \pm 6.34 \mathrm{nmol} / \mathrm{g}$ wet wt.; $p<0.05$ ) and the medulla (from $18.39 \pm 0.31 \mathrm{nmol} / \mathrm{g}$ wet wt. to $50.18 \pm 0.66 \mathrm{nmol} / \mathrm{g}$ wet wt.; $p<0.05)$ (Table 1). The renal histopathological lesions are shown in Fig. 3. In the cortex, vanadate induced glomerular hypertrophy, loss of brush border membrane of proximal tubules, tubular cell swelling, dilatation, and cytoplasmic vacuolization (Fig. 3D). In the outer medulla, vanadate demolished brush border membranes of the PTs, while the lumen of TALH was expanded (Fig. 3E). General morphology of the inner medulla was maintained. Some collecting ducts presented with edema (Fig. 3F).

\section{DISCUSSION}

This is the first in vivo study to simultaneously examine the effect of vanadate on renal $\alpha_{1}-\mathrm{Na}, \mathrm{K}$-ATPase protein abundance/localization, on renal cAMP and MDA levels, and on renal tissue injury. Vanadate administration for 10 days can significantly suppress renal $\alpha_{1}-\mathrm{Na}, \mathrm{K}-\mathrm{ATPase}$ protein abundance (Fig. 1), diminish $\alpha_{1}-\mathrm{Na}$, K-ATPase immunostaning intensity in both the cortex and medulla (Fig. 2), enhance cAMP accumulation (Table 1), augment renal MDA levels (Table 1), and induce renal histopathological lesions (Fig. 3).

Our present study is the first to demonstrate that vanadate induces cAMP accumulation in the kidney approximately two-fold (Table 1). It have been shown that cAMP could influence on $\mathrm{Na}$, K-ATPase property. In vitro stud- 

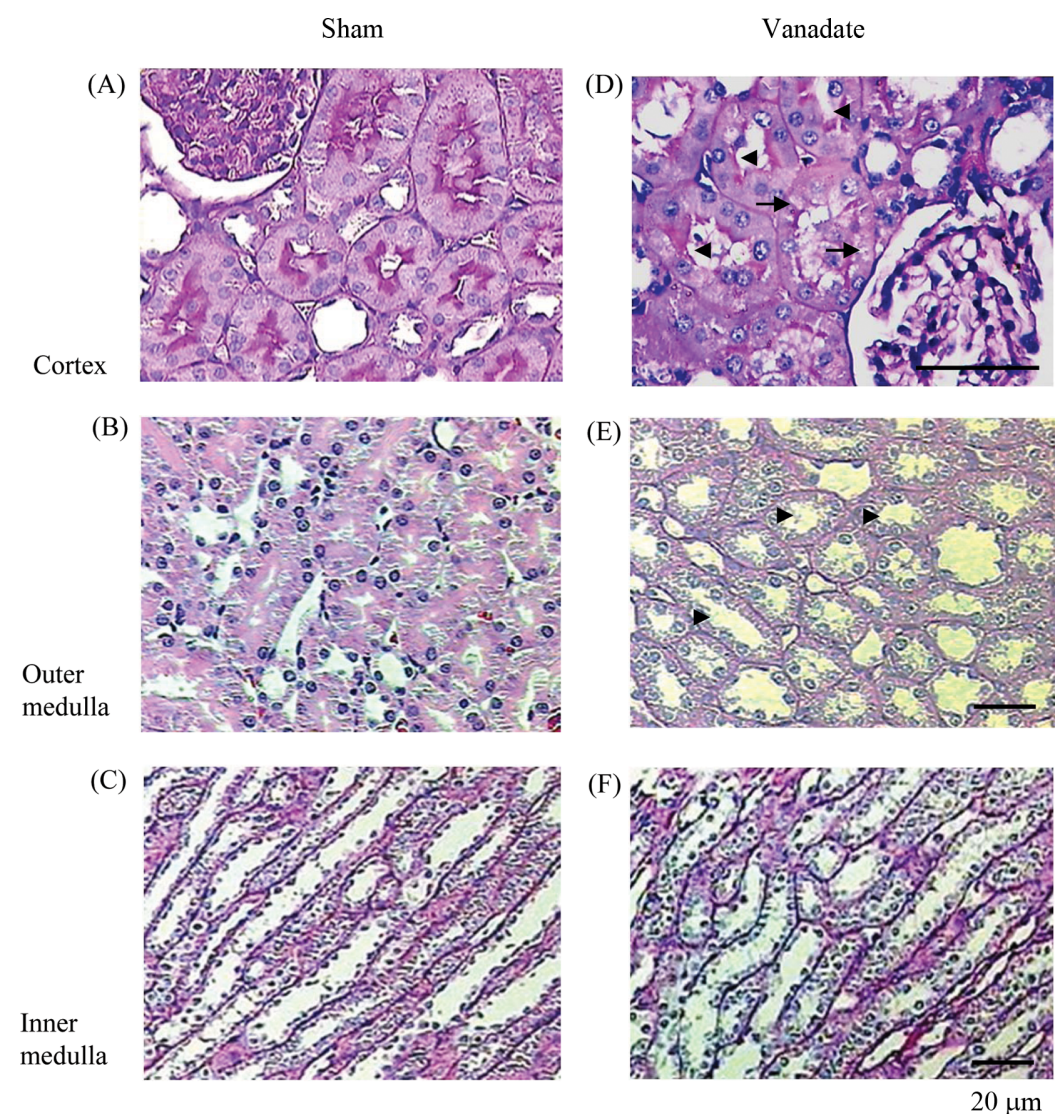

Fig. 3. Morphological changes of the kidney after 10 days of vanadate injection. Histological findings PAS stained tissues in the cortex $(A, D)$, outer medulla $(B, E)$, and inner medulla $(C, F)$ from sham $(A-C)$, and vanadate $(D-F)(n=5 / g r o u p)$. Vanadate induced glomerular hypertrophy, loss of brush border membrane of proximal tubules (arrow heads), tubular cell swelling, dilatation, and cytoplasmic vacuolization (arrows). Bar scale $=20 \mu \mathrm{m}$.

ies showed that cAMP inhibits $\mathrm{Na}$, K-ATPase activity in the CCD, the liver's and brain's plasma membranes of rats $(17,24,25)$. The suggested mechanisms that cAMP reduces $\mathrm{Na}, \mathrm{K}$-ATPase activity have been proposed. Cyclic AMP phosphorylates Ser943 on the $\alpha$ subunit of $\mathrm{Na}$, K-ATPase and reduces its activity in the rat TALH $(26,27)$. Moreover, in renal tubular cells, cAMP-regulated phosphoprotein inhibited $\mathrm{Na}$, K-ATPase activity by inactivating protein phosphatase-1 (28). In addition, vanadate can directly block a conformational change on the cytoplasmic side of unphosphorylated Na, K-ATPase (29-31). Therefore, it is likely that vanadate can inhibit $\mathrm{Na}, \mathrm{K}$-ATPase action via both the indirect (via increased cAMP) and direct pathways. The present study is the first to show that vanadateinduced cAMP accumulation diminished $\alpha_{1}-\mathrm{Na}$, K-ATPase protein abundance in the rat kidney. The precise mechanism that vanadate reduces this protein remained unveiled.

Histological evaluation of the kidneys illustrated that vanadate induced structural damage to the glomeruli and especially to the proximal tubules (Fig. 3D, 3E). It has been reported that proximal tubules are the main site of action of vanadate in the nephron (32). Several studies documented that vanadate induces more cellular cytotoxicity in the proximal tubules than in the other segments $(9,33,34)$. Interestingly, the present results show that the suppression of $\alpha_{1}-\mathrm{Na}$, K-ATPase protein was pronounced in the proximal tubules with morphological changes (Fig. 2D, 2E, Table 3). This result suggests another mechanism in which vanadate reduces $\alpha_{1}$-Na, K-ATPase protein levels through the direct destruction of renal tissues.

Compared with the sham group, the toxicity of vanadium producing lipid peroxidation in our present study resulted in MDA accumulation in renal tissues (Table 1). These data are consistent with previous studies $(35,36)$. Vanadium is a trace metal in the environment and in biological systems that readily undergoes redox reactions in the presence of reductants, oxygen, or reduced products $(1,2,37)$. Vanadate induced lipid peroxidation is due to vanadate-stimulated oxidation of substances produced free radical molecules. It has been shown that in vitro vanadium oxidizes thiols and $\mathrm{NAD}(\mathrm{P}) \mathrm{H}$ through free radical mechanisms (38-42). A previous study demonstrated that 
vanadate enhances tissue destruction via free radicalinduced DNA damage (43). Collectively, the enhanced lipid peroxidation in the present study may be a potential factor underlying vanadate toxicity.

The consequences of vanadate-induced kidney injury in the present study caused increases in blood urea nitrogen, plasma creatinine, and fractional excretion of all studied electrolytes (Table 1,2). Notably, vanadate-induced hypokalemia (Table 1) may be due to the inhibitory effect on $\mathrm{H}, \mathrm{K}-\mathrm{ATPase}$ activity via competitively binding with ATP at the catalytic site (44).

In conclusion, these in vivo findings demonstrate that vanadate stimulates renal cAMP and MDA accumulation but suppresses renal $\alpha_{1}$-Na, K-ATPase protein levels. Vanadate contributes to structural and functional deterioration of the kidney.

\section{ACKNOWLEDGMENTS}

This research was supported by The Ratchadapiseksompoth Research Fund (RA 24/51), Faculty of Medicine, Chulalongkorn University.

Received July 26, 2017; Revised January 10, 2018; Accepted March 13, 2018

\section{REFERENCES}

1. Korbeck, J., Baranoska-Bosiacka, I., Gutowka, I. and Chlubek, D. (2012) Biochemical and medical importance of vanadium compounds. Acta Biochim. Pol., 59, 195-200.

2. Chlubek, D. (2015) The role of vanadium in biology. Metallomics, 7, 730-742.

3. Dafnis, E. and Sabatini, S. (1994) Biochemistry and pathophysiology of vanadium. Nephron, 67, 133-143.

4. Sitprija, V. and Eiam-Ong, S. (1998) Vanadium and metabolic problems in Vanadium in the Environment. Part 2: Health Effects (Nriagu, J. Ed.). John Wiley \& Sons, Chicago, pp. 91-120.

5. Dafnis, E., Spohn, M., Lonis, B., Kurtzman, N.A. and Sabatini, S. (1992) Vanadate causes hypokalemic distal renal tubular acidosis. Am. J. Physiol. Renal Physiol., 262, F449F453.

6. Cantley, L.C., Josephson, L., Warner, R., Yanagisan, M., Lechene, C. and Guidotti, G. (1977) Vanadate is a potent (Na,K)-ATPase inhibitor found in ATP derived from muscle. J. Bio. Chem., 252, 7421-7423.

7. Clough, L.D. (1985) Inhibition of rat cardiac and renal $\mathrm{Na}, \mathrm{K}-\mathrm{ATP}$ ase by high sodium concentrations and vanadate. Life Sci., 37, 799-807.

8. Grantham, J.J. and Glyn, I.M. (1979) Renal Na,K-ATPase determinants of inhibition by vanadium. Am. J. Physiol. Renal Physiol., 236, F530-F535.

9. Boscolo, P., Carmingnani, M., Volpe, A.R., Felaco, M. and Giuliano, G. (1994) Renal toxicity and arterial hypertension in rats chronically exposed to vanadate. Occup. Environ.
Med., 51, 500-503.

10. Donaldson, J., Hemming, R. and LaBella, F. (1985) Vanaduim exposure enhances lipid peroxidation in the kidney of rats and mice. Can. J. Physiol. Pharmacol., 63, 196199.

11. Mahmoud, K.E., Shalahmetova, T., Deraz, S. and Umbayev, B. (2011) Combined effect of vanadium and nickel on lipid peroxidation and selected parameters of antioxidant system in liver and kidney of male rat. Afr. J. Biotechnol., 10, 18319-18325.

12. Russanov, E., Zaporowska, H., Ivancheva, E., Kirkova, M. and Konstantinova, S. (1994) Lipid peroxidation and antioxidant enzymes in vanadate-treated rats. Comp. Biochem. Physiol. Pharmacol. Toxicol. Endocrinol., 107, 415-421.

13. Al-Bayati, M.A., Giri, S.N., Raabe, O.G., Rosenblatt, L.S. and Shifrine, M. (1989) Time and dose-response study of the effects of vanadate on rats: morphological and biochemical changes in organs. J. Environ. Pathol. Toxicol. Oncol., 9, 435-455.

14. Krawietz, W., Werdan, K. and Erdmann, E. (1980) Stimulation of human cardiac adenylate cyclase by vanadate. Basic Res. Cardiol., 75, 433-437.

15. Hackbarth, I., Schmitz, W., Scholz, H., Wetzel, E., Erdmann, E., Krawietz, W. and Philipp, G. (1980) Stimulatory effects of vanadate on cyclic AMP levels in cat papillary muscle. Biochem. Pharmacol., 29, 1429-1432.

16. Schmitz, W., Hackbarth, I., Scholz, H. and Wetzel, E. (1980) Effects of vanadate on the c-AMP system of the heart. Basic Res. Cardiol., 75, 438-443.

17. Satoh, T., Cohen, H.T. and Katz, A.I. (1992) Intracellular signaling in the regulation of renal Na-K-ATPase. I. Role of cyclic AMP and phospholipase A2. J. Clin. Invest., 89, 1496-1500.

18. Eiam-Ong, S., Sinphitukkul, K., Manotham, K. and EiamOng, S. (2013) Rapid nongenomic action of aldosterone on protein expressions of $\mathrm{Hsp} 90(\alpha$ and $\beta$ ) and $\mathrm{pc}-\mathrm{Src}$ in rat kidney. BioMed Res. Int., 2013, 346480.

19. Eiam-Ong, S., Sinphitukkul, K., Manotham, K. and EiamOng, S. (2014) Rapid action of aldosterone on protein expressions of protein kinase $\mathrm{C}$ alpha and alphal sodium potassium adenosine triphosphatase in rat kidney. J. Steroids. Horm. Sci., 5, 125.

20. Eiam-Ong, S., Chaipipat, M., Manotham, K. and Eiam-Ong, S. (2017) Rapid action of aldosterone on protein levels of sodium-hydrogen exchangers and protein kinase C-beta Isoforms in rat kidney. Int. J. Endocrinol., 2017, 2975853.

21. Eiam-Ong, S., Jerawatana, R., Kittikowit, W., Mannontarat, R., Tirawatnapong, T. and Eiam-Ong, S. (2009) Effect of vanadate and potassium depletion on renal $\mathrm{H}$, K-ATPase protein expression. Asian Biomed., 3, 517-523.

22. Seujang, Y., Kittikowit, W., Eiam-Ong, S. and Eiam-Ong, S. (2006) Lipid peroxidation and renal injury in ischemic reperfusion: Effect of angiotensin inhibition. J. Med. Assoc. Thai., 89, 1686-1693.

23. Son, J.Y., Kang, Y.J., Kim, K.S., Kim, T.H., Lim, S.K., Lim, H.J., Jeong, T.C., Choi, D.W., Chung, K.H., Lee, B.M. and Kim, H.S. (2014) Evaluation of renal toxicity by combination exposure to melamine and cyanuric acid in male sprague-dawley rats. Toxicol. Res., 30, 99-107. 
24. Tria, E., Luly, P., Tomasi, V., Trevisani, A. and Barnabei, O. (1974) Modulation by cyclic AMP in vitro of liver plasma membrane Na-K-ATPase and protein kinases. Biochim. Biophysic. Acta, 343, 297-306.

25. Lingham, R.B. and Sen, A.K. (1982) Regulation of rat brain $\mathrm{Na}^{+}-\mathrm{K}^{+}$-ATPase activity by cyclic AMP. Biochim. Biophysic. Acta, 688, 475-485.

26. Fisone, G., Chang, S.X., Nairn, A.C., Czernik, A.J., Hemmings, H.C., Hoog, J.O., Bertorello, A.M., Kaiser, R. and Bergman, T. (1994) Identification of the phosphorylation site for cAMP-dependent protein kinase on $\mathrm{Na}, \mathrm{K}$-ATPase and effects of site-directed mutagenesis. J. Biol. Chem., 269, 9368-9373.

27. Kiroytcheva, M., Cheval, L., Carranza, M., Martin, P., Favre, H., Doucet, A. and Ferailie, E. (1999) Effect of cAMP on the activity and the phosphorylation of $\mathrm{Na}$, K-ATPase in rat thick ascending limb of Henle. Kidney Int., 55, 1819-1831.

28. Aperia, A., Fryckstedt, J., Svensson, L., Hemmings, H.C. and Nairn, A. (1991) Phosphorylated Mr 32,000 dopamineand cAMP-regulated phosphoprotein inhibits Na, K-ATPase activity in renal tubule cells. Proc. Natl. Acad. Sci. U.S.A., 88, 2798-2801.

29. Grantham, J.J. (1980) The renal sodium pump and vanadate. Am. J. Physiol. Renal Physiol., 239, F97-F106.

30. Phillips, T.D., Nechay, B.R. and Heidelbaugh, N.D. (1983) Vanadium: chemistry and the kidney. Fed. Proc., 42, 29692973.

31. Montes, M.R., Monti, J.L. and Rossi, R.C. (2012) E2-> E1 transition and $\mathrm{Rb}^{+}$release induced by $\mathrm{Na}^{+} / \mathrm{K}^{+}$-ATPase. Vanadate as a tool to investigate the interaction between $\mathrm{Rb}^{+}$and E2. Biochim. Biophysic. Acta, 1818, 2087-2093.

32. Higashi, Y. and Bello-Reuss, E. (1980) Effects of sodium orthovanadate on whole kidney and single nephron function. Kidney Int., 18, 302-308.

33. Soussi, A., Abdennabi, R., Ghorbel, F., Murat, J.C. and El Feki, A.F. (2017) Ameliorated effects of (-)-epigallocatechin gallate against toxicity induced by vanadium in the kidneys of Wistar rats. Biol. Trace Elem. Res., 180, 239-245.

34. de la Torre, A., Granero, S., Mayayo, E., Corbella, J. and
Domingo, J.L. (1999) Effect of age on vanadium nephrotoxicity in rats. Toxicol. Lett., 105, 75-82.

35. Scibior, A., Zaporowska, H. and Niedwiecka, I. (2010) Lipid peroxidation in the kidney of rats treated with $\mathrm{V}$ and/or $\mathrm{Mg}$ in drinking water. J. Appl. Toxicol., 30, 487-496.

36. Scibior, A., Zaporowska, H., Ostrowski, J. and Banach, A. (2006) Combined effect of vanadium (V) and chromium (III) on lipid peroxidation in liver and kidney of rats. Chem. Biol. Interact., 159, 213-222.

37. Stern, A., Yin, X., Tsang, S.S., Davison, A. and Moon, J. (1993) Vanaduim as a modulator of cellular regulatory cascades and oncogene expression. Biochem. Cell Biol., 71, 103-112.

38. Stacey, N.H. and Klassen, C.D. (1981) Comparison of the effects of metals in cellular injury and lipid peroxidation in isolated rat hepatocytes. J. Toxicol. Environ. Health, 7, 139147.

39. Liochev, S. and Fridovich, I. (1989) Vanadate-stimulated oxidation of NAD(P)H. Free Rad. Biol. Med., 6, 617-522.

40. Liochev, S. and Fridovich, I. (1990) Vanadate-stimulated oxidation of $\mathrm{NAD}(\mathrm{P}) \mathrm{H}$ in the presence of biological membranes and other sources of $\mathrm{O}_{2}^{-}$. Archs. Biochem. Biophys., 279, 1-7.

41. Stankiewicz, P.J., Stern, A. and Davidson, A.J. (1991) Oxidation of NADH by vanadium: kinetics, effects of ligands and role of $\mathrm{H}_{2} \mathrm{O}_{2}$ or $\mathrm{O}_{2}$. Archs. Biochem. Biophys., 287, 8-17.

42. Capella, L.S., Gefe, M.R., Silva, E.F., Mitidieri, O.A., Lopes, A.G., Rumjanek, V.M. and Capella, M.A. (2002) Mechnisms of vanadate-induced cellular toxicity: role of cellular glutathione and NADPH. Arch. Biochem. Biophys., 406, 65-72.

43. Shi, X., Jiang, H., Mao, Y., Ye, J. and Saffinotti, U. (1996) Vanadium (IV) mediated free radical generation and related 2 '-deoxyguanosine hydroxylation and DNA damage. Toxicology, 106, 27-38.

44. Faller, L.D., Rabon, E. and Sachs, G. (1983) Vanadate binding to the gastric H, K-ATPase and inhibition of the enzyme's catalytic and transport activities. Biochemistry, 22, 46764685 . 